\title{
p16 expression in colorectal adenocarcinoma: marker of aggressiveness and morphological types
}

Running head: p16 expression in colorectal carcinoma

Alfred King-Yin Lam ${ }^{1}$, M.B.B.S, M.D., Ph.D., F.R.C.P.A.

Kate Ong ${ }^{2}$, B.Sc., M.Sc.

Mahmound Jafari Giv, M.B.B.S.

Yik-Hong $\mathrm{Ho}^{2}$, M.B.B.S., M.D., F.R.A.C.S.

${ }^{1}$ Division of Pathology (School of Medicine), Griffith University, Gold Coast,

Queensland, Australia

${ }^{2}$ Division of Surgery (School of Medicine) and North Queensland Centre for Cancer

Research (Australian Institute of Tropical Medicine), James Cook University,

Townsville, Queensland, Australia

Correspondence and/or reprint requests:

Professor Alfred Lam

Foundation Chair Professor and Head of Pathology

Griffith Medical School

Medicine and Oral Health Centre

PMB 50 GCMC Bundall

Gold Coast QLD 9726

Australia

Phone +61 7 56780718; Fax +61 7 56780708; E-mail: a.lam@griffith.edu.au

Source of support: The project was supported by a grant from the Queensland Cancer Fund and scholarship from Royal College of Pathologists of Australasia. 


\section{STRUCTURED ABSTRACT}

Aim: The aim of the present study is to investigate the clinicopathological roles of p16 expression in a large cohort of patients with colorectal adenocarcinoma with tight methodology and close follow-up.

Methods: p16 protein expression was investigated in 194 patients (102 men, 92 women) with colorectal adenocarcinomas by immunohistochemistry. The findings were correlated with their clinicopathological features.

Results: p16 protein was detected in 80\% (155 of 194) of patients with colorectal carcinoma. The $\mathrm{p} 16$ protein was more often detected in male patients with colorectal cancers ( $86 \%$ versus $73 \%, \mathrm{p}=0.03)$. p16 protein expression was more often seen in carcinomas in the rectum, sigmoid and descending colon compared to more proximal colon ( $90 \%$ versus $61 \%, \mathrm{p}=0.001$ ). The $\mathrm{p} 16$ protein was more often detected in well or moderately-differentiated colorectal adenocarcinoma than poorly-differentiated colorectal adenocarcinoma ( $84 \%$ versus $63 \%, \mathrm{p}=0.009$ ). The level of expression of $\mathrm{p} 16$ protein is related to the lymph nodal status $(\mathrm{p}=0.004)$ and the TNM staging of the colorectal carcinoma $(\mathrm{p}=0.008)$.

Conclusion: p16 protein expression was common in colorectal adenocarcinomas. The expression correlated with gender of the patient, distal location, differentiation and staging of the tumour. The findings suggest that p16 plays an important role in cancer pathogenesis and has implications for improving the clinical management.

KEYWORDS: p16, expression, colorectal adenocarcinoma 


\section{INTRODUCTION}

Colorectal cancer is amongst the most common malignancy found in the Western world and usually ranks high in incidence and mortality among malignancies in those countries [1]. Globally, colorectal cancers accounted for about 1 million new cases in 2002 (9.4\% of the world total). In terms of incidence, colorectal cancers rank fourth in frequency in men and third in women. There is at least a 25-fold variation in occurrence of colorectal cancer worldwide. The highest incidence rates are in North America, Australia/New Zealand and Western Europe. The incidence of colorectal cancer is also increasing in many Asian countries [2]. The main pathology type of the colorectal cancer is adenocarcinoma, though some other variants can occur [3, 4]. Surgery is the mainstay of treatment, with adjuvant chemotherapy and radiotherapy for specific subgroups of patients. The disease imposes a significant health threat despite the fact that survival from the disease has been improved. There is evidence that research contributes directly to improve the care of patients with colorectal cancer by more accurately refining prognosis and selecting the most appropriate adjuvant therapy for individual patients with colorectal carcinoma [5]. In order to do this, novel tissue-based prognostic indicators should been sought at the molecular level.

The p16 suppressor gene is one of the most commonly studied candidates in the pathogenesis of human neoplasia [6]. p16 gene encodes p16 protein that competes with cyclin D for binding to CDK4. This inhibits the ability of the cyclin D-CDK4 complex to phosphorylate Rb (retinoblastoma) protein, thus causing cell cycle arrest at late $\mathrm{G}_{1}$ phase. In recent years, the status of p16 alternations in cancer can be studied by immunohistochemistry. Strong p16 expression has been reported in many neoplasia 
[7,8]. Nevertheless, to date, the major clinical application of p16 expression has been in the field of cervical pathology [9].

In colorectal cancers, the clinicopathological roles of p16 protein expression have been studied but with no agreement between their findings [10-18]. This is likely related to small patient numbers. Therefore, we investigated p16 expression in a large consecutive cohort of patients with colorectal cancer with good quality follow-up in order to determine more definitely its relationship with the different clinicopathological parameters. The current series is the one of the largest studies to critically determine the roles of this biomarker in colorectal cancer. 


\section{MATERIALS AND METHODS}

\section{Data collection}

One hundred and ninety-four consecutive patients (102 men, 92 women) with primary colorectal adenocarcinoma were recruited from the Townsville Hospital in North Queensland. The age, gender, clinical presentation, management and survival data of these patients were prospectively collected in a computerized database. The actuarial survival rate of the patients was calculated from the date of surgical resection of the colorectal carcinomas to the date of death or last follow-up. Management was by a preagreed standardized multidisciplinary protocol supervised by a senior specialist colorectal surgeon. None of the rectal cancer patients had undergone neoadjuvant radiotherapy or chemotherapy prior to surgery. Pathological diagnosis was also standardized and reviewed by committee criteria, chaired by a senior academic pathologist with a special interest in the field. Follow-up was routinely at 3 monthly intervals for the first 2 years, 6 monthly for the subsequent 3 years, and yearly thereafter. Serum carbino-embryonic antigen (CEA) levels were taken before each visit and imaging investigations performed as clinically appropriate. Colonoscopy was performed at 1 year after surgery, and repeated as appropriate to the findings and other clinical features at follow-up. Informed consent was obtained for the Townsville Hospital ethics committee.

The tissue samples were collected prospectively. The site and size (maximum length) of the colorectal cancers were recorded. Standard blocks were then taken, fixed in $10 \%$ formalin and embedded in paraffin wax. Histological sections were cut and stained for haematoxylin and eosin for light microscopic examination. The histological subtypes were classified using the World Health Organization (WHO) criteria [19]. 
Mucinous carcinoma was defined as an adenocarcinoma with more than $50 \%$ of the tumour composing of extracellular mucin. The carcinomas were staged according to TNM (Tumour, Lymph node and Metastases) classification adopted in American Joint Committee on Cancer [20]. 


\section{P16 staining}

The antibody $\mathrm{p} 16^{\text {INK4a }}$ used was a mouse monoclonal antibody supplied by Biocare Medical (Cat \# CM020, Walnut Creek, CA, USA). From the selected paraffin blocks, 4um paraffin sections were de-waxed in xylene and re-hydrated through graded alcohols and water. Tissue endogenous peroxidase activity was blocked by incubating sections with $3 \% \mathrm{H}_{2} \mathrm{O}_{2}$. Antigen retrieval was performed by incubation in $10 \mathrm{mM}$ citrate buffer $(\mathrm{pH}=6.0)$ in a pressure cooker for 20 minutes. After the slides were cooled, they were rinsed with distilled water and then washed with Tris Buffer Saline $(\mathrm{TBS}, \mathrm{pH}=$ 7.6). From this stage onwards, TBS was used as the washing solution throughout the immunohistochemistry staining procedure. Sections were then treated with $10 \%$ normal goat serum to block the non-specific binding. Endogenous biotin activity of tissue was blocked by the Biotin blocking system (Dako). Sections were incubated in p16 primary antibody at a dilution $1: 25$, for 60 minutes at $37^{0} \mathrm{C}$. The secondary antibody, biotinylated goat anti mouse (at a dilution of 1:400, Dako) was applied for 30 minutes at $37^{\circ} \mathrm{C}$, followed by the incubation of 1:100 StreptABC (Avidin biotin complex, Dako) for 30 minutes at $37^{0} \mathrm{C}$.

\section{Assessment of immunostaining}

The slides were then immersed into the liquid diaminobenzidine and substratechromogen system (Dako). Finally, the sections were counter stained with Mayer’s haematoxylin and dehydrated through graded alcohol, cleared in xylene. Negative controls were sections treated using the same techniques as above, but with omission of the primary antibody. In each experiment, paraffin blocks of colorectal carcinoma known to be strongly positive for p16 protein were used as positive controls. Examination of p16 
staining was done using a standard light microscope. Brown nuclear stain was regarded as positive. The positive cases of p16 were graded semi-quantitatively into 3 categories; $1+, 2+, 3+(1+:<30 \%$ of the tumour cells were positive; $2+: \geq 30$ to $<70 \%$ of the tumour cells were positive; $3+: \geq 70 \%$ or more of the tumour cells were positive).

\section{Statistical analysis}

Comparisons between groups were performed using the chi-square test, Fisher's exact test and student t-test. Fisher's exact test or likelihood ratio was used for categorical variables. Student t-test with Yates correction was used for continuous variables. The significance of various parameters on survival was analysed by the Kaplan-Meier method with log-rank test and multivariate Cox's regression. Significance level was taken at $\mathrm{p}<0.05$. All statistical tests were performed with the program, Statistical Package for Social Sciences (SPSS version 14.0, Chicago, IL). 


\section{Results}

\section{Clinico-pathological data}

The median age of the patients was 64 (range, 24 to 92) years. The mean diameter of the tumours was $4.5 \mathrm{~cm}$ (range, 0.7 to $16.0 \mathrm{~cm}$ ). The tumours were located in caecum in $11 \%(n=22)$, ascending colon in $8 \%(n=16)$, transverse colon in $15 \%(n=30)$, descending colon in 5\% (n=9), sigmoid colon in 25\% $(n=48)$ and rectum in $36 \%(n=69)$. In the proximal portion of the large intestine (caecum, ascending colon and transverse colon), $58 \%$ of the tumors occurred in women. Conversely, in the distal portion of the large intestine (descending colon, sigmoid colon and rectum), 58\% of the tumours were noted in men. The gender difference in tumour location was statistically significant $(p=0.04)$.

In this series, 37 mucinous carcinomas in the colorectum were noted. The clinicopathological features of 36 cases were documented in our previous study [3]. The other colorectal cancers were 157 typical adenocarcinomas. Overall, the adenocarcinomas were well-differentiated in 9\% $(n=17)$, moderately-differentiated in $73 \%(n=142)$ and poorly-differentiated in $18 \%(n=35)$. The adenocarcinomas as classified according to TNM were: stage I in 26\% ( $n=50)$, II in 32\% ( $n=62)$, III in 30\% $(\mathrm{n}=58)$ and IV in $12 \%(\mathrm{n}=24)$.

\section{p16 expression and clinicopathological parameters}

p16 protein was detected in 80\% (155 of 194) of patients with colorectal adenocarcinoma (Table 1). The non-neoplastic mucosa showed no evidence of p16 protein expression (Figure 1A). Staining was found to be grade $1 \mathrm{in} 32 \%(\mathrm{n}=62)$, grade 2 in $27 \%(n=52)$ and grade 3 in $21 \%(n=41)$ of the patients. In grades 2 and 3 staining, 
the p16 protein expression was located at the nuclei as well as the cytoplasm of the tumour cells. These high levels of p16 protein expression were regarded as p16 overexpression (Figure 1B).

There was no significant difference between the frequency of p16 protein expression in mucinous carcinoma and typical adenocarcinoma. On the other hand, p16 expression showed significant correlation with the differentition of the carcinomas (Figure 1C). The p16 protein was more often detected in well or moderatelydifferentiated colorectal adenocarcinoma than poorly-differentiated colorectal adenocarcinoma (84\% versus 63\%, $\mathrm{p}=0.009)$. Also, the level of $\mathrm{p} 16$ protein expression was higher (with grade 2 or 3 expression) in well or moderately-differentiated colorectal adenocarcinoma $(\mathrm{p}=0.034)$. In addition, within a tumour, the $\mathrm{p} 16$ expression was often seen in well-differentiated glandular structures rather than isolated poorly-differentiated tumour cells.

The p16 protein was more often detected in male patients with colorectal cancers (86\% versus $73 \%, p=0.03$ ). The expression did not differ from those without with respect to age at presentation $(\mathrm{p}=0.44)$. Also, $\mathrm{p} 16$ protein expression was often seen in carcinomas in the distal colorectum (the rectum, sigmoid colon or descending colon) than in proximal portions of the colon (90\% versus $61 \%, \mathrm{p}=0.001)$. This difference in $\mathrm{p} 16$ protein expression between the proximal and distal colorectum was significant in both males and females ( $\mathrm{p}=0.0001$ and 0.005 respectively). Also, the level of p16 protein expression in the distal colorectum was often higher than the proximal colon $(p=0.003)$.

The level of expression of p16 protein is related to the lymph nodal status and the TNM staging of the colorectal carcinoma. Sixty-one per cent (25 of 41) of patients with high grade (grade 2 or grade 3) p16 expression had lymph node metastases whereas only 
35\% (53 of 153) patients with grade 1 or negative p16 expression had lymph node metastases ( $\mathrm{p}=0.004)$. In addition, $61 \%$ (25 of 41 ) patients with grade 2 or grade 3 p16 protein expression had advanced stages (stage 3 or 4) carcinoma whereas only 37\% (57 of 153) patients with grade 1 or negative p16 protein expression had carcinoma in advanced stages $(p=0.008)$.

\section{Survival analysis}

Follow-up data were available for all the patients. Twenty-nine percent $(n=57)$ of the patients died of causes related to the colorectal cancer in the study period. The overall median survival rate for patients with the cancer was 61 months. By KaplanMeier log-rank survival and Cox-multivariate analysis, survival of the patients with colorectal cancer was only associated with the TNM stages of the tumours (Figure 2A). The mean survival of patient with early stages (stages 1 or 2 ) cancers was 70 months whereas that of advanced stages (stages 3 or 4$)$ was 41 months $(p=0.0001)$.

Survival of patients was not significantly related to patients’ age, gender and tumours' differentiation, location, p16 protein expression ( $>>0.05)$. Patients with p16 protein overexpression had slightly poorer survival rates than other patients. The difference in survival was more prominent in female patients (Figure 2B). The mean survival was 74 months in female patients with low level or negative p16 protein expression whereas the mean survival was 53 months in patients with p16 protein overexpression. However, Kaplan-Meier analysis did not show that the level of p16 expression was significantly predicative of survival $(\mathrm{p}=0.1)$. Patients with loss of $\mathrm{p} 16$ expression did not show any survival difference from other patients $(p>0.05)$. 


\section{DISCUSSION}

The relationships between p16 protein expression and colorectal adenocarcinoma have been investigated in a few studies [10-18] (Table 2). The frequency of expression of p16 protein in colorectal adenocarcinoma reported varied from $17 \%$ to $99 \%$, with the majority of studies showed p16 expression in more than two third of colorectal cancers. In this study, we noted that p16 protein was expressed in $80 \%$ of the colorectal adenocarcinoma and approximately half (48\%) of the tumors showed p16 overexpression. The frequency of p16 protein expression noted in the study was similar to the frequency of p16 protein expression in colorectal mucinous adenocarcinoma [3]. Also, we noted no significant differences between typical adenocarcinomas and mucinous adenocarcinomas. We are the first to describe significantly higher p16 protein expression in males with colorectal adenocarcinoma. The overall high prevalence of p16 expression in colorectal adenocarcinoma implies that p16 alternations played an important role in the pathogenesis of this cancer.

.p16 is a nucleoprotein, the presence of staining in both the nuclei and the cytoplasm supports the finding thatp16 gene is overexpressed. The change in the subcellular location of the over-expressed nucleoprotein may account for the pathogenesis of colorectal adenocarcioma. It is apparent that the overexpression of p16 rather than the loss of its protein contributes to the pathogenetic mechanism of colorectal adenocarcinoma. Because of the frequent overexpression of p16 protein in colorectal adenocarcinoma, p16 overexpression may be use as a marker for colorectal adenocarcinoma for selected patients with histological diagnostic difficulty.

In the recent years, researchers have demonstrated that cancers located in the right (proximal) and left (distal) colorectum can be distinguished by clinical and molecular 
criteria [21-23]. Proximal colorectal tumours, when compared to distal tumours, were more often found in older age, females and benefit from 5-fluorouracil-basedchemotherapy. Right sided tumours also showed significantly less nuclear $\beta$-catenin and p53 overexpression than left-sided tumours [21-23]. With regard to p16 protein expression, Schineier-Stock et al noted that there was a loss of p16 expression in proximal tumors in a study of 43 patients with colorectal cancers [13]. Our group also noted that p16 protein expression was more often noted in mucinous carcinoma of the distal colorectum [3]. In this study, we confirmed the findings in 194 colorectal adenocarcinomas. The difference in p16 protein expression between the two sites of the large intestine was independent of the difference in gender distribution of the right and left sided tumours. Thus, the differences in gene expression in different location in colorectum exist and this may have important implications with specifically targeted therapeutic regimens in the future.

There is often a phenotypic-genotypic correlation with regard to cell cycle proteins. For instance, our group demonstrated that p53 expression was related to the differentiation in many different carcinomas [24-26]. For p16 protein expression, Palmqvist et al. have noted that the expression was more in well-differentiated adenocarcinoma and Tada et al noted that the expression was lost in mucinous or poorlydifferentiated adenocarcinoma $[10,14]$. In this study, p16 expression was demonstrated to be more often found in well and moderately-differentiated colorectal carcinomas. P16 overexpression was also commonly seen in these grades of colorectal adenocarcinomas. In addition, within a tumour, the p16 expression was often seen in well-differentiated glandular structure rather than isolated poorly-differentiated tumour cells. Thus, p16 expression was shown to be a marker for differentiation in colorectal adenocarcinoma. 
The prognostic role of p16 protein have been investigated in four studies

$[12,14,15,18]$. Norrie et. al. and Tada et. al. reported no relationship of patients’ survival with p16 protein expression. Zhao et. al. noted that the survival of patients was poorer with weak p16 protein expression survival [18]. Also, Cui et al reported that both loss of p16 protein expression and p16 protein overexpression were associated with poorer survival rates [15]. In the current study with a larger cohort of patients, we also noted that patients with negative or low level expression of p16 protein enjoyed good survival whereas those with high level of p16 protein expression had poorer survival. Unfortunately, the difference did not reach statistical significance. Thus, this large study with prospective collection of data, tight methodology and close follow-up suggest the p16 protein overexpression or loss of p16 protein expression did not alone correlate with prognosis of patients with colorectal cancer. On the other hand, it was confirmed that high levels of p16 protein expression were associated with advanced tumour stages and lymph node metastases. Thus, p16 protein overexpression was demonstrated to be a marker of aggressive biological behaviour and could be used as a potential prognostic marker in colorectal adenocarcinoma.

In conclusion, the clinicopathological roles of p16 protein expression were studied in a depth in a large cohort of patients with colorectal adenocarcinoma. The expression correlated with location, differentiation and staging of the tumour. These findings imply that p16 alternation is important in the pathogenesis of colorectal adenocarcinoma and p16 protein expression can be a potential biomarker for selected patients with colorectal adenocarcinoma.

Acknowledgements: The authors would like to thank the staff in Queensland Health Pathology Services in providing access to slides and blocks for the study. 


\section{REFERENCES}

1. Parkin DM, Bray F, Ferlay J, Pisani P. Global cancer statistics 2002. CA Cancer J Clin 2005; 55:74-108.

2. Sung JJ, Lau JY, Goh KL, Leung WK; Asia Pacific Working Group on Colorectal Cancer. Increasing incidence of colorectal cancer in Asia: implications for screening. Lancet Oncol. 2005;6:871-6.

3. Lam AK, Ong K, Ho YH. Colorectal mucinous adenocarcinoma: the clinicopathologic features and significance of p16 and p53 Expression. Dis Colon Rectum 2006; 49:1275-1283.

4. Lam AK, Ho YH. Primary squamous cell carcinoma of the rectum in a patient on immunosuppressive therapy. Pathology. 2006;38:74-6.

5. Alvarado MD, Jensen EH, Yeatman TJ. The potential role of gene expression in the management of primary and metastatic colorectal cancer. Cancer Control. 2006;13:27-31.

6. Kim WY, Sharpless NE. The regulation of INK4/ARF in cancer and aging. Cell. 2006;127:265-75.

7. Yuen PW, Man M, Lam KY, Kwong YL. Clinicopathological significance of p16 gene expression in the surgical treatment of head and neck squamous cell carcinomas. J Clin Pathol. 2002;55:58-60.

8. Lam AK, Lo CY, Leung P, Lang BH, Chan WF, Luk JM. Clinicopathological Roles of Alterations of Tumor Suppressor Gene p16 in Papillary Thyroid Carcinoma. Ann Surg Oncol. 2006 Dec 31;

9. McCluggage WG. Immunohistochemistry as a diagnostic aid in cervical pathology. Pathology. 2007;39:97-111.

10. Palmqvist R, Rutegard JN, Bozoky B, Landberg G, Stenling R. Human colorectal cancers with an intact p16/cyclin D1/pRb pathway have up-regulated p16 expression and decreased proliferation in small invasive tumor clusters. Am J Pathol. 2000;157:1947-53.

11. McKay JA, Douglas JJ, Ross VG, Curran S, Loane JF, Ahmed FY, Cassidy J, McLeod HL, Murray GI. Analysis of key cell-cycle checkpoint proteins in colorectal tumours. J Pathol. 2002;196:386-93.

12. Norrie MW, Hawkins NJ, Todd AV, Meagher AP, O'Connor TW, Ward RL. Inactivation of p16INK4a by CpG hypermethylation is not a frequent event in colorectal cancer. J Surg Oncol. 2003;84:143-50. 
13. Schneider-Stock R, Boltze C, Peters B, Hopfner T, Meyer F, Lippert H, Roessner A. Differences in loss of p16INK4 protein expression by promoter methylation between left- and right-sided primary colorectal carcinomas. Int J Oncol. 2003;23:1009-13.

14. Tada T, Watanabe T, Kazama S, Kanazawa T, Hata K, Komuro Y, Nagawa H. Reduced p16 expression correlates with lymphatic invasion in colorectal cancers. Hepatogastroenterology. 2003;50:1756-60.

15. Cui X, Shirai Y, Wakai T, Yokoyama N, Hirano S, Hatakeyama K. Aberrant expression of pRb and p16(INK4), alone or in combination, indicates poor outcome after resection in patients with colorectal carcinoma. Hum Pathol. 2004;35:1189-95.

16. Carneiro FP, Ramalho LN, Britto-Garcia S, Ribeiro-Silva A, Zucoloto S. Immunohistochemical expression of p16, p53, and p63 in colorectal adenomas and adenocarcinomas. Dis Colon Rectum. 2006;49:588-94.

17. Zhao P, Mao X, Talbot IC. Aberrant cytological localization of p16 and CDK4 in colorectal epithelia in the normal adenoma carcinoma sequence. World $\mathrm{J}$ Gastroenterol. 2006;12:6391-6.

18. Zhao P, Hu YC, Talbot IC. Expressing patterns of p16 and CDK4 correlated to prognosis in colorectal carcinoma. World J Gastroenterol. 2003;9:2202-6.

19. Hamilton SR, Vogelstein B, Kudo S, et al. Carcinoma of the colon and rectum. In: WHO Classification of Tumours: Pathology and Genetics of Tumours of Digestive System. S.R. Hamilton \& L.A. Aaltonen (eds). IARC press, Lyon (France), 2000 pp 105-119.

20. Greene FL, Page DL, Fleming ID, Fritz A, Balch CM, Haller DG, Morrow M (eds). AJCC cancer staging manual, edition 6, Springer-Verlag, Berlin/Heidelberg/New York/London/Paris/Tokyo/Hong Kong, 2002.

21. Iacopetta B. Are there two sides to colorectal cancer? Int J Cancer 2002;101:4038.

22. Kapiteijn E, Liefers GJ, Los LC, et al. Mechanisms of oncogenesis in colon versus rectal cancer. J Pathol 2001;195:171-8.

23. Birkenkamp-Demtroder K, Olesen SH, Sorensen FB, Laurberg S, Laiho P, Aaltonen LA, Orntoft TF. Differential gene expression in colon cancer of the caecum versus the sigmoid and rectosigmoid. Gut. 2005;54:374-84.

24. Lam KY, Law S, Lo T, Tung HM, Wong J. The clinicopathological significance of p21 and p53 expression in esophageal squamous cell carcinoma: an analysis of 153 patients. Am J Gastroenterol; 1999; 94: 2060-68. 
25. Lam KY, Chan ACL, Chan KW, Leung ML, Srivastava G. Expression of p53 and its relationship with human papillomavirus in penile carcinomas. Eur J Surg Oncol 1995;21:613-16.

26. Lam KY, Lo CY, Chan KW, Wan KY. Insular and anaplastic carcinoma of the thyroid: A 45-year comparative study at a single institution and a review of the significance of p53 and p21. Ann Surg 2000;231:329-38 


\section{Figure legend}

Figure 1. p16 protein detected by immunohistochemistry: (A) showing the non-neoplastic colonic epithelium was negative for p16 protein and adenocarcinoma was positive (B) showing the high percentage of positive immunostaining in the nuclei and cytoplasm of the moderately-differentiated adenocarcinoma. (C) showing the focal immunostaining in poorly-differentiated adenocarcinoma.

Figure 2. (A)The relationship between patients's survival and stages of the colorectal carcinoma (B) The relationship between survival of female patients and level of expression of p16 (p16 +: overexpression; p16 -: negative or low expression). 


\section{Table 1.}

Clinicopathological parameters of p16 positive and negative colorectal adenocarcinoma

\begin{tabular}{llll} 
Parameters & $\begin{array}{l}\text { positive } \\
(\mathrm{n}=155)\end{array}$ & $\begin{array}{l}\text { negative } \\
(\mathrm{n}=39)\end{array}$ & p value \\
\hline Male: female & $88: 67$ & $14: 25$ & $\mathbf{0 . 0 3}$ \\
Mean age (years) & 65 & 64 & 0.67 \\
Mean tumour & 4.4 & 4.7 & 0.44 \\
size (cm) & & & \\
$\begin{array}{l}\text { Location } \\
\text { Proximal colon }\end{array}$ & 42 & & $\mathbf{0 . 0 0 0 1}$ \\
Distal colorectum & 113 & 27 & \\
Tumour histology & & 12 & 0.50 \\
Conventional & 127 & & \\
Mucinous & 28 & 30 & \\
Grade & & 9 & $\mathbf{0 . 0 0 9}$ \\
Well/Mod & 133 & &
\end{tabular}


Table 2 Relationship between immunohistochemical expression of p16 and clinicopathological data and colorectal adenocarcinoma

\begin{tabular}{|c|c|c|c|c|}
\hline Author/year/country & \%positive & demographic data & pathological features & prognosis \\
\hline $\begin{array}{l}\text { Palmqvist/2000/ } \\
\text { Sweden }\end{array}$ & $75 / 92(82 \%)$ & - & $\begin{array}{l}\text { more in grade } 1 \text { tumour, } \\
\text { not correlate with stage, tumour type, }\end{array}$ & - \\
\hline McKay/2002/UK & $184 / 249(74 \%)$ & not correlate with age, gender & not correlate with grade, differentiation & - \\
\hline Norrie/2003/Australia & $148 / 161(92 \%)$ & not correlate with gender & $\begin{array}{l}\text { loss expression associated with grade } 3 \text { tumour } \\
\text { not correlate with type, site }\end{array}$ & no relationship \\
\hline $\begin{array}{l}\text { Schineider-Stock/ } \\
\text { 2003/Germany }\end{array}$ & $29 / 43(67 \%)$ & not correlate with age, gender & $\begin{array}{l}\text { loss expression in proximal tumour } \\
\text { not correlate with grade and stage }\end{array}$ & - \\
\hline Tada/2003/Japan & $82 / 84(98 \%)$ & - & $\begin{array}{l}\text { loss expression in mucinous/grade } 3 \text { tumour, } \\
\text { advanced T stage \& lymphatic invasion } \\
\text { not correlate with stage, lymph node metastases }\end{array}$ & no relationship \\
\hline Cui/2004/Japan & $45 / 117(38 \%)$ & not correlate with age, gender & $\begin{array}{l}\text { strong expression associate with size } \\
\text { not correlate with grade, stage, site } \\
\text { tumour type, lymph node metastases }\end{array}$ & $\begin{array}{l}\text { worst in overexpression } \\
\text { or loss expression }\end{array}$ \\
\hline Carneiro/2006/Brazil & $5 / 30(17 \%)$ & - & not correlate with grade & - \\
\hline $\begin{array}{l}\text { Zhao/2003 \& 2006/ } \\
\text { UK \& China }\end{array}$ & $73 / 74(99 \%)$ & - & not correlate with grade and stage & poorer in low expression \\
\hline Present study & $155 / 194(80 \%)$ & $\begin{array}{l}\text { correlate with gender, } \\
\text { not with age }\end{array}$ & $\begin{array}{l}\text { strong expression in distal colorectum } \\
\text { well/moderate differentiation, advanced stages, } \\
\text { lymph node metastases, not correlate with } \\
\text { tumour type, size }\end{array}$ & no relationship \\
\hline
\end{tabular}


Figure 1A

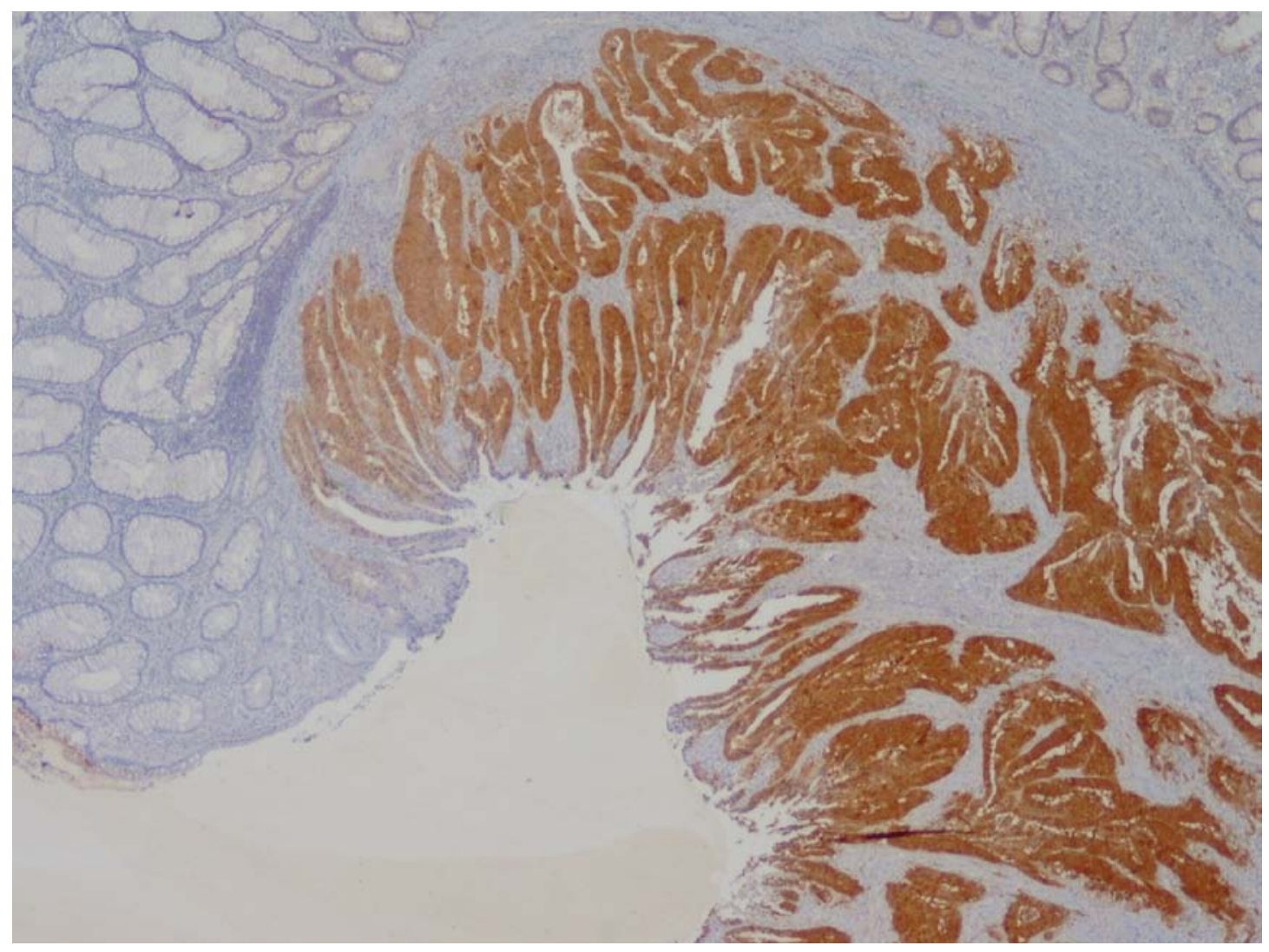


Figure 1B

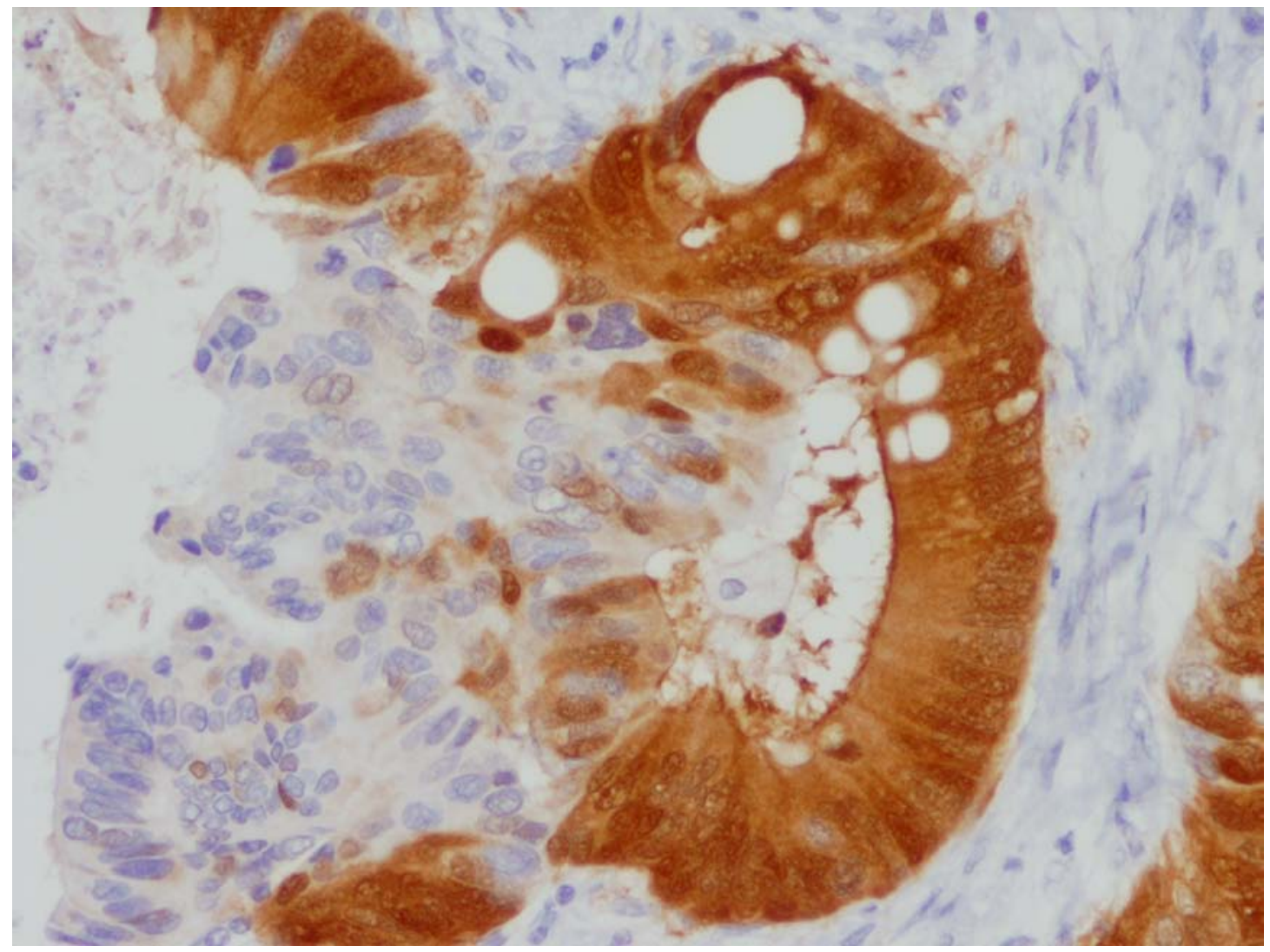


Figure 1C

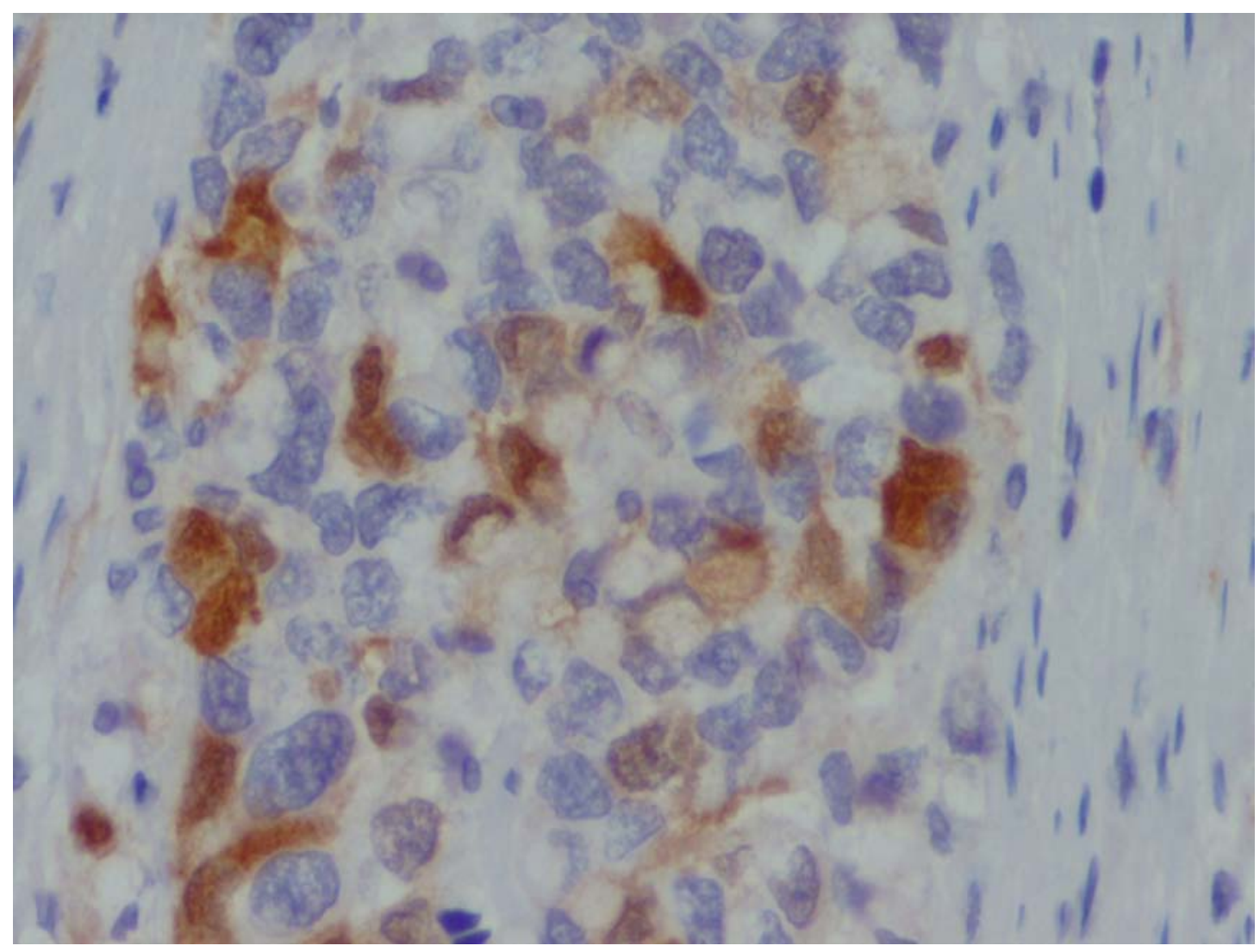


Figure 2A

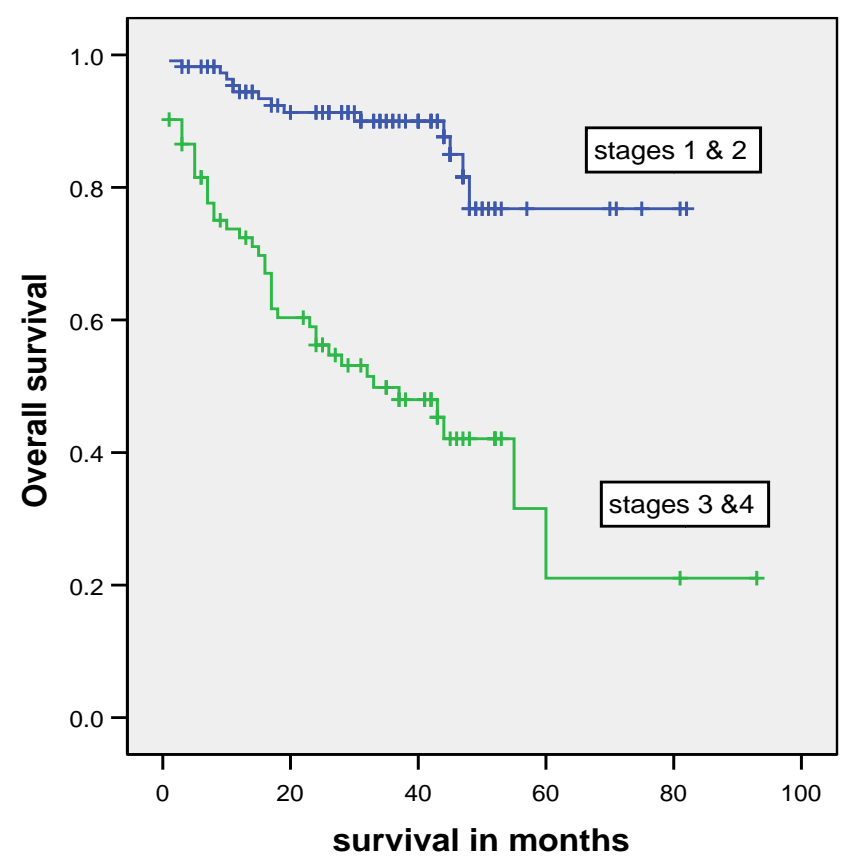


Figure 2B

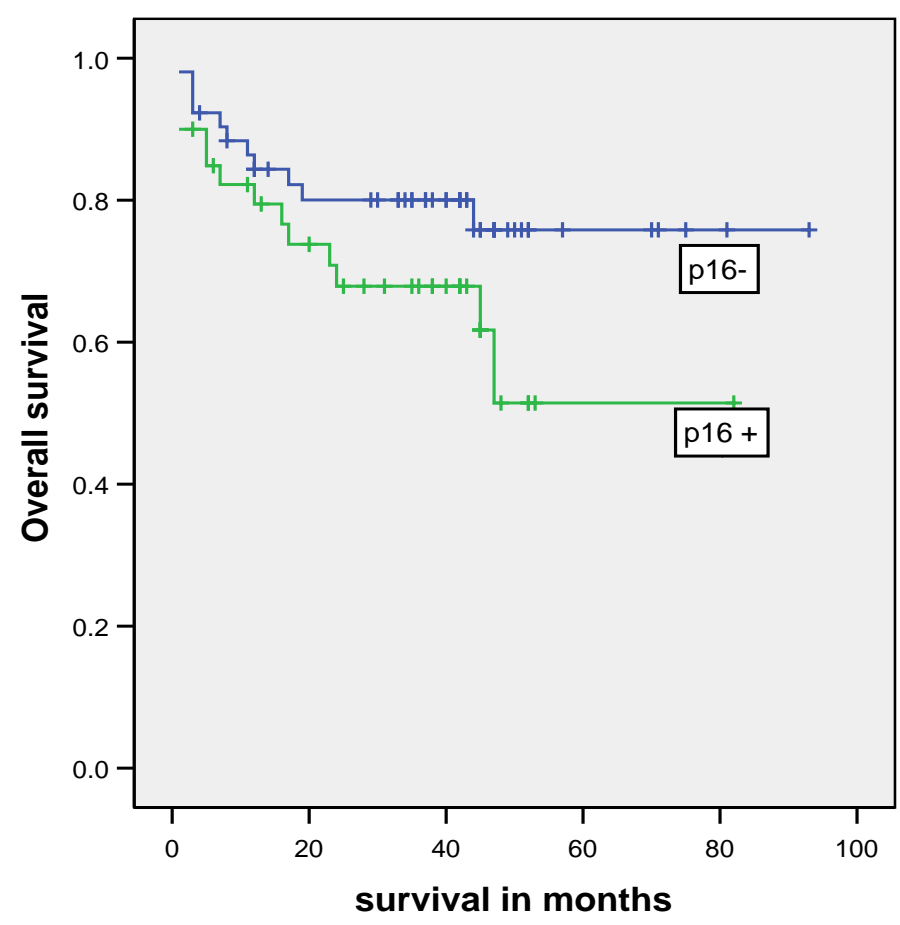

